\title{
A Universidade Aberta do Brasil e a democratização do Ensino Superior público
}

Paulo Romualdo Hernandes a

\section{Resumo}

Analisam-se, neste estudo, Decretos-leis e documentos oficiais que regulamentam a educação a distância no Brasil, bem como a criação da Universidade Aberta do Brasil (UAB) como política pública de expansão, democratização e interiorização do Ensino Superior público em tempos de educação on-line. Estuda-se, ainda, em documentos da Capes/UAB e também do Fundo para Desenvolvimento da Educação (FNDE), o papel do novo ator social que surge no processo de ensino e aprendizagem dos cursos superiores a distância: o tutor. Constatou-se que os cursos superiores a distância promovidos pelo sistema UAB trazem importantes avanços para a educação a distância quando comparada com a educação a distância tradicional, que empregava como linguagem de comunicação suportes estáticos, como televisão, rádio, livros, sobretudo nas possibilidades de relações intersubjetivas; contudo, eles também apresentam algumas limitações.

Palavras-chave: Universidade Aberta do Brasil. Ensino superior a distância. Tecnologia educacional. Educação on-line.

\section{Introdução}

O Ensino Superior público oferecido pelo sistema Universidade Aberta do Brasil (UAB) caracteriza-se no domínio da educação formal, portanto, "se sujeita à pedagogia (a teoria da educação), cria situações próprias para o seu exercício, produz os seus métodos, estabelece suas regras e tempos e constitui executores especializados. A Educação formal é o momento histórico quando aparecem a escola, o aluno e o professor" (BRANDÃO, 1981, p. 26). A escola, nesse caso, é desterritorializada fisicamente e reterritorializada no ambiente virtual, na rede de computadores, que deve mediar o encontro entre os sujeitos da aventura de ensinar e aprender, o professor e o aluno, como determina o Decreto-lei

\footnotetext{
a Universidade Federal de Alfenas. Alfenas, MG, Brasil.
} 
$\mathrm{n}^{\mathrm{o}}$ 5.622, de dezembro de 2005 (BRASIL, 2005), que regulamentou o artigo 80 da Lei no 9.394, de 20 de dezembro de 1996 (BRASIL, 1996), que trata da Educação a distância (EAD) no Brasil.

A caracterização da EAD como modalidade de educação formal, em que professor e aluno encontram-se separados espacial ou temporalmente e são mediados pelas tecnologias de informação e comunicação para o processo de ensino e aprendizagem, está em consonância com as transformações que vêm ocorrendo no decorrer desta última década, em virtude do surgimento de novas tecnologias e meios de comunicação. Com a popularização do uso do computador e, sobretudo, da internet no Brasil a partir da década de 1990, a educação a distância pôde tornar-se educação on-line: "Modalidade de educação a distância realizada via internet, cuja comunicação ocorre de forma sincrônica ou assincrônica" (ALMEIDA, 2003, p. 332). A educação on-line viabilizou a interação direta entre professor e aluno, aluno e aluno, aluno e tutor - um dos principais entraves da EAD tradicional, que tinha como tecnologias mediadoras a escrita, o rádio, a televisão, entre outros aparatos tecnológicos estáticos, quando o professor apenas preparava material de estudos e o estudante era um autoaprendiz. Nos nossos dias, de educação on-line, o estudante tornou-se um "aprendente autônomo", que é responsável pela sua aprendizagem, pelo seu próprio desenvolvimento, "que é sujeito principal de sua aprendizagem" (BELLONI, 2003, p. 41), mas não um autoaprendiz que tem no professor apenas um produtor de material didático.

Inicialmente, a finalidade deste artigo é fazer um balanço entre análises favoráveis e desfavoráveis da educação a distância, apontando que as novas tecnologias de informação e comunicação (TICS) teriam minimizado algumas das principais críticas, notadamente a impossibilidade de se estabelecer uma relação interativa entre professor-aluno e aluno-aluno (PATTO, 2013). Em um segundo momento, apresenta-se um estudo sobre a criação da UAB, órgão instituído em 2005 pelo Ministério da Educação para congregar as Instituições Públicas de Ensino Superior nos esforços de oferta de curso superior a distância. Neste estudo, analisa-se em documentos oficiais as finalidades, os objetivos, avanços e limites da educação a distância. No modelo de cursos ofertados pela UAB, surgirá um novo ator social no processo de ensino e aprendizagem: o tutor a distância ou professor-tutor (ABREU-E-LIMA; ALVES, 2011).

O foco de estudo, então, está centrado no avanço que a educação on-line possibilitou para a EAD. Nos cursos ofertados pela UAB, no entanto, parece ter havido um híbrido de educação a distância no modelo de informação de pronta entrega (broadcast) e educação on-line - hibridismo que provocou o 
aparecimento do "professor-tutor" no processo de ensino e aprendizagem nessa modalidade de ensino.

\section{A educação a distância seria a educação do futuro ou a falência da educação?}

Benjamim (1994), no seu clássico estudo sobre a "reprodutividade tecnológica", classificou o cinema como uma arte sem aura, reprodutora das ideias da classe dominante, que, diferente do teatro, não permitia a interação. Na tela, a imagem estática reproduzida em tempos e lugares diversos, "criada por um grêmio de especialistas: produtor, diretor, operador, engenheiro de som ou da iluminação, etc." (BENJAMIN, 1994, p. 178). Um elemento estaria ausente na fotografia, no cinema, na televisão: "o aqui e agora" (BENJAMIN, 1994, p. 167). Em certo sentido, essa crítica pode ser refletida em relação à EAD - pelo menos aquela que se desenvolveu no Brasil antes do surgimento da educação on-line, educação a distância que utiliza suportes de comunicação estáticos, broadcast, ou seja, "entregar a informação ao aluno" (ALMEIDA, 2003, p. 330). Informação produzida por um grêmio de especialistas e entregue em programas educativos de rádio - como as transmissões de cursos pela Rádio Nacional, criada por Roquete Pinto, em 1922, ou os programas educativos Minerva, durante o governo militar, ou o uso de textos impressos e da comunicação via correio, promovidos pelo Instituto Universal, a partir dos anos 1940. Recentemente, utilizando como suporte de comunicação a televisão, as teleaulas, inicialmente veiculadas pela Televisão Cultura e mais tarde pela Rede Globo, são exemplos típicos desse formato de educação a distância de pronta entrega.

Esse modelo de educação foi anunciado pelo artigo 80 da Lei ${ }^{\circ} 9.394 / 96$, LDBEN, e regulamentado pelo Decreto $\mathrm{n}^{\circ} 2.494$, de 10 de fevereiro de 1998, que define em seu artigo $1^{\circ}$ :

Educação a distância é uma forma de ensino que possibilita a autoaprendizagem, com a mediação de recursos didáticos sistematicamente organizados, apresentados em diferentes suportes de informação, utilizados isoladamente ou combinados, e veiculados pelos diversos meios de comunicação (BRASIL, 1998).

Esse formato de educação a distância é estático, como a tela de um cinema, pois constitui uma forma de ensino mediada por recursos didáticos apresentados em diferentes suportes de informação, veiculados por meios de comunicação. Não promove a interação professor-aluno ou a socialização entre os participantes da 
relação de ensino e aprendizagem. É uma modalidade de educação em que o professor prepara o material de ensino - a videoaula, por exemplo - e o aluno recebe um pacote de informações, tornando-se, por obrigação da modalidade de ensino e não por opção, um autoaprendiz.

Educação de "caráter essencialmente informativo e documentário, ela não tem como formar a experiência do pensamento" (PATTO, 2013, p. 312), pois não é "habitada por professores e alunos cujas relações face a face tecem a vida institucional" (PATTO, 2013, p. 312). Nessa modalidade de "educação", o aluno não é um aluno; o professor, por sua vez, gravando (imprimindo) suas aulas, torna-se um cachimbo que não é um cachimbo, ou seja, é um professor, mas não é um professor:

Valendo-nos da frase Isto não é um cachimbo, sob o desenho de um cachimbo uma tela célebre de Magritte, podemos afirmar três coisas; sobre o estúdio Isto não é uma sala de aula; sobre a apresentação do programa, Isto não é uma professora; sobre o que ela faz diante da câmera, Isto não é uma aula. Uma aula virtual é apenas simulacro de uma aula presencial (PATTO, 2013, p. 310).

Essa aula de estúdio, aula simulacro, em que o aluno não é um aluno, mas um espectador, traria alguns problemas próprios da "telemáquina", pois a "transformação de conteúdos pedagógicos em produtos audiovisuais" (PATTO, 2013, p. 306) não permitiria ao estudante vivenciar o caráter singular de uma aula presencial, o aqui e agora. Assim, não seria possível experimentar os assuntos apresentados no aqui e agora da sala de aula, sobre o que foi dito pelo professor, que, como vimos, não é um professor, mas um ator que segue um roteiro preestabelecido e bem ensaiado. O estudante tem nas telas luminosas da televisão, do computador, nos programas de rádio, nas fitas de vídeo, nos textos escritos, um produto pronto e acabado para ser assimilado, apreendido, consumido. $\mathrm{O}$ aluno ouve, assiste, lê o professor, ou o ator, quantas vezes for preciso até aprender, letra por letra, o que foi dito; faz os exercícios, resolve as atividades, compara suas respostas com as resoluções das atividades apresentadas no caderno de respostas do livro didático e pronto: aprendeu a lição. Que lição? Aquela que foi criada pelos produtores de aulas, objeto de consumo, para ser consumida por ele.

Em aulas transmitidas por rádio, a voz soberana do professor ilumina as ideias do estudante ouvinte e não pode ser questionada. Na escrita, como ensinou Sócrates (PLATÃO, 1975) ao jovem Fedro em um bosque fora dos muros da 
cidade de Atenas, o professor imprime suas ideias em um texto para ser lido por seus discípulos, solitariamente à sombra de um plátano, alijando do processo de ensino e aprendizagem o debate, o diálogo e a dialética. A aula radiofônica ou escrita é, também, material de consumo para o estudante.

Essa característica estática da educação a distância, nos simulacros de aula, em que não há encontro face a face de professor e aluno, aluno e colegas de sala, e não há possibilidade de emancipação, já que se nega a "dialogicidade como essência da educação" (FREIRE, 1988, p. 68), foi amenizada nos nossos dias, com o aparecimento da educação on-line. Com as novas tecnologias, há possibilidades de interação nas redes virtuais para promover o encontro entre educador e educando, mesmo que estejam em lugares ou tempos diversos. A educação on-line possibilita encontros virtuais entre todos os participantes do processo educativo na rede social. Essa possibilidade permite uma relação intersubjetiva entre os participantes do processo educativo. A diferença entre a aula radiofônica, escrita ou de estúdio e a aula on-line seria a mesma apontada por Adorno e Horkheimer (1985, p. 115) para o rádio e para o telefone: o telefone "liberal permitia que os participantes ainda desempenhassem o papel de sujeito. Democrático, o rádio transforma-os a todos igualmente em ouvintes". A educação mediada por tecnologias on-line é menos democrática que o rádio e outros modos de comunicação estáticos, pois exige dos participantes do processo educativo conhecimentos aprimorados e, além disso, seu custo é alto; porém, assim como o telefone, possibilita a relação entre sujeitos tendo a máquina como mediadora.

O surgimento de tecnologias em que os participantes pelo processo educativo pudessem ser sujeitos, e não apenas ouvintes, trouxe novo ânimo para a educação a distância. Especialistas (ARAÚJO, 2007; LÉVY, 1999; MORAN, 2007) nas novas tecnologias e em educação a distância chegaram a defender que, com as inovações tecnológicas dos novos tempos, sobretudo a internet, a EAD seria mais produtiva que a educação presencial: em uma sala de aula presencial, a maioria dos alunos não estaria realmente presente e participativa (ARAÚJO, 2007) como na aula digital, em que o aluno, mediado pela máquina, tem contato direto com o professor. São adeptos da ideia de que as novas tecnologias de comunicação e informação proporcionarão mudanças totais no método de ensino e aprendizagem, sendo esse novo meio a educação do futuro próximo:

Aos poucos, a sociedade vai se conectando à internet, com consequências profundas no futuro próximo. Quanto mais conectada a sociedade, mais a educação poderá ser diferente. Não haverá tanta necessidade de ficarmos todos no mesmo lugar, para aprender 
ao mesmo tempo e com as mesmas pessoas. A conectividade abre possibilidades muito variadas de aprendizagem personalizada, flexível, ubíqua, integrada (MORAN, 2007, p. 125).

A educação mediada pelas novas tecnologias dos nossos dias, nos aplicativos para desenvolver educação a distância, sobretudo por intermédio da rede, pode proporcionar as mesmas condições de sala de aula, com a vantagem de que o estudante e o professor, o estudante e seus colegas, o professor e seus colegas de outras disciplinas e universidades, o estudante e outros professores de outras disciplinas e universidades podem debater suas questões, ensinamentos e aprendizagens em tempos e lugares diferentes. É possível, ainda, em cursos mediados pela internet, sair da sala de aula virtual e navegar por outros sites, enciclopédias eletrônicas, dicionários virtuais, encontrar textos científicos on-line, imagens, fotos de satélites e vídeos (LÉVY, 1999). O estudante pode ser autônomo em sua aprendizagem que a educação mediada pelas mídias pode possibilitar (BELLONI, 2003). Os participantes do processo educativo podem compartilhar suas ideias, seus textos, seus vídeos, suas músicas, propor fóruns, entre outras atividades, para toda a coletividade que com ele participa de um curso, de uma disciplina. Essa condição está em consonância com a "proatividade do aluno" que, segundo Arieira et al. (2009, p. 322), é uma "marca da educação contemporânea, na qual o aluno repositório de informações e conteúdos não tem mais seu lugar na sociedade".

A educação a distância pode deixar de ser uma forma de ensino de autoaprendizagem, que se utiliza de recursos didáticos estáticos apresentados em suportes de informação veiculados pelos diversos meios de comunicação, como determinava o Decreto-lei $\mathrm{n}^{\circ} 2.494$, e passar a ser uma modalidade de ensino mediada pelas tecnologias de informação e comunicação, em que professores e estudantes podem desenvolver atividades educativas em lugares ou tempos diversos, como propugna o Decreto-lei $n^{0} 5.622$ (BRASIL, 2005), com a possibilidade de interação intersubjetiva. Nessa nova caracterização, o professor deixa de ser um ator e o aluno deixa de ser um espectador, pois ambos podem dialogar, interagir sincronamente por chat, webconferência, videoconferência, utilizando as redes sociais, ou assincronamente, em fóruns, por e-mail, utilizando as redes sociais, entre outras tecnologias de informação e comunicação. O professor pode deixar de ser um produtor de aulas para consumo e o aluno pode deixar de ser um consumidor passivo dos ensinamentos, produzindo os seus próprios conhecimentos e socializando com o professor e com seus colegas de turma. O principal recurso da EAD on-line está na possibilidade de se estabelecer entre os participantes "um processo educacional colaborativo no qual todos se comunicam com todos e podem 
produzir conhecimentos, como ocorre nas comunidades virtuais colaborativas" (ALMEIDA, 2003, p. 333).

A educação on-line torna possível um professor atuar junto com o aluno, mediando e estimulando sua aprendizagem, provocando reflexões importantes, propiciando "interaprendizagem e aprendizagem significativas do aluno" (ALMEIDA, 2003, p. 335) e acompanhando seu desenvolvimento individualmente. Segundo os defensores das possibilidades de uso da internet para a educação, um dos avanços seria a formação de grupos de discussão em chats e fóruns, que possibilitam o "acesso de alunos e professores como usuários do sistema para compartilharem informações sobre determinado assunto de interesse comum ou até participando do mesmo projeto, local, nacional ou internacional" (BEHRENS, 2000, p. 99). $\mathrm{Na}$ EAD, "não existe a figura do professor como único dono da verdade e do poder de saber tudo": o aluno participa do processo de aprendizagem trocando conhecimentos com o professor e com outros alunos do curso, intervindo, participando ativamente e contribuindo para a construção do aprendizado (BITTENCOURT; MERCADO, 2014, p. 469).

Ambientes colaborativos virtuais são criados com o uso da internet, seja por meio de webconferência, de videoconferências, chats, fóruns ou e-mails. Evidentemente, essa potencialidade de uso da internet depende de projetos educativos que possibilitem uso desses recursos para promover a interação entre os envolvidos no processo educativo, sobretudo professores e estudantes.

\section{O sistema Universidade Aberta do Brasil nos tempos da educação on-line}

O sistema Universidade Aberta do Brasil (UAB) foi criado pelo Ministério da Educação em 2005 (ZUIN, 2006) e regulamentado pelo Decreto ${ }^{\circ} 5.800$, de 8 de junho de 2006, constituindo uma parceria dos três níveis governamentais (federal, estadual e municipal) com Instituições Públicas de Ensino Superior (IPES) e "demais interessados" (ZUIN, 2006, p. 943), para oferecer cursos de Ensino Superior na modalidade a distância. Surge em um período em que os novos meios de informação e comunicação, sobretudo a internet, estavam disponíveis, possibilitando as interações professor-estudante e estudante-estudante, na rede.

No artigo $1^{\circ}$ do Decreto que institui o sistema, temos que a finalidade da UAB está voltada "para o desenvolvimento da modalidade a distância, com a finalidade de expandir e interiorizar a oferta de cursos e programas de Educação Superior no País" (BRASIL, 2006). "Surge, de acordo com a Secretaria de Educação a 
Distância do MEC, como uma alternativa primordial para viabilizar a formação de 30\% dos estudantes brasileiros até 2011" (ZUIN, 2006, p. 943). Pretende-se, então, empregar os meios tecnológicos para a expansão e interiorização do Ensino Superior público no Brasil, a fim de cumprir com o que consta do Plano Nacional de Educação. Portanto, prover e expandir cursos superiores na modalidade a distância para diminuir a desigualdade de oferta nas diferentes regiões do país (BRASIL, 2001) são letras de um mesmo discurso governamental: "forma de acelerar o cumprimento de dois compromissos desse Plano, em relação à Educação Superior" (SEGENREICH, 2009, p. 207). Nesse sentido, a educação a distância é "claramente tomada como modalidade de ensino para aceleração rápida da expansão de vagas no Ensino Superior" (ALONSO, 2010, p. 1319).

É fundamental e urgente a democratização do Ensino Superior público no Brasil, país continental, empregando outros meios que não a educação presencial. Mas, essa ampliação tem que ser elaborada com estratégias, projetos pedagógicos e metodologias apropriadas para aproveitar-se os recursos e as inovações proporcionadas pelas novas tecnologias de informação e comunicação (OLIVEIRA, 2010). A educação a distância on-line é diferente da educação presencial e deve ser diferenciada da educação a distância broadcast. Além disso, não basta oferecer cursos superiores a distância para resolver alguns entraves na ampliação de vagas no Ensino Superior. É "preciso cuidar para que essa expansão venha acompanhada por criterioso diagnóstico e localização de demanda [...] para se priorizar determinadas políticas nesse sentido" (ALONSO, 2010, p. 1326), a fim de se levar em consideração o aluno que ingressará nesses cursos. E, sobretudo, é necessário que os cursos superiores ofertados pelo sistema UAB não se tornem paliativos apenas para que o Estado cumpra com suas obrigações legais, sendo "outra ação fragmentada tomada pelo poder público", que não resolve definitivamente e com qualidade a demanda pelo Ensino Superior público no Brasil (ARIEIRA et al., 2009, p. 319).

No artigo $1^{\circ}$ do Decreto $\mathrm{n}^{\circ} 5.800$ estão definidos os objetivos do sistema UAB. O primeiro deles é "oferecer, prioritariamente, cursos de licenciatura e de formação inicial e continuada de professores da Educação Básica" (BRASIL, 2006). Objetiva-se, portanto, resolver outro grave problema da educação no Brasil, a falta de professores com formação superior, além de promover cursos de formação continuada para a melhoria da qualidade da Educação Básica no país utilizando a EAD para agilizar o processo. Os estudantes podem ingressar nesses cursos por falta de escolha e não por interesse em cursos a distância, o que traz problemas, pois os alunos, para não serem receptores passivos de informações e realizadores automáticos de atividades, precisam ter conhecimentos elaborados para o uso das tecnologias e serem maduros para gerir seu tempo de 
estudo (BELLONI, 2003). O segundo objetivo pretende empregar a educação a distância para capacitar dirigentes, gestores e trabalhadores em Educação Básica no país. Os artigos III - "oferecer cursos superiores nas diferentes áreas do conhecimento", IV - "ampliar o acesso à educação superior pública", $\mathrm{V}$ - "reduzir as desigualdades de oferta de Ensino Superior entre as diferentes regiões do país" e VI - "estabelecer amplo sistema nacional de educação a distância" (BRASIL, 2006) repetem a finalidade de criação do sistema UAB: democratizar, expandir, interiorizar o Ensino Superior público por meio da educação a distância. Esses objetivos parecem estar mais voltados à resolução de problemas e dificuldades para o Ensino Superior público no Brasil, de modo rápido e quantitativo, do que promover cursos a distância fazendo uso das novas tecnologias de informação e comunicação. O objetivo VII - "fomentar o desenvolvimento institucional para a modalidade de educação a distância, bem como a pesquisa em metodologias inovadoras de Ensino Superior apoiadas em tecnologias de informação e comunicação" (BRASIL, 2006) parece estar em maior consonância com as novas possibilidades da educação on-line no ensino a distância.

No artigo $2^{\circ}$ de estabelecimento da UAB está o entrave maior para a democratização, expansão e interiorização do Ensino Superior público de qualidade no país utilizando as novas tecnologias de informação e comunicação para mediar a relação intersubjetiva entre professor e aluno: "O Sistema UAB cumprirá suas finalidades e objetivos sócio-educacionais em regime de colaboração da União com entes federativos, mediante a oferta de cursos e programas de educação superior a distância por instituições públicas de Ensino Superior, em articulação com polos de apoio presencial". Os cursos não são regulares e fazem parte de um convênio de cooperação tripartite, em que, como determina o artigo $3^{\circ}$, o "Ministério da Educação firmará convênios com as instituições públicas de Ensino Superior, credenciadas nos termos do Decreto $\mathrm{n}^{0} 5.622$, de 19 de dezembro de 2005, para o oferecimento de cursos e programas de educação superior a distância no Sistema UAB" (BRASIL, 2006).

Esse convênio para oferta de cursos de graduação a distância tripartite, por exemplo, entre a União, Instituições Públicas de Ensino Superior e Municípios ou Estados ou o Distrito Federal, impõe algumas dificuldades para a promoção de educação superior utilizando as inovações trazidas pelas novas tecnologias. Do lado da União, por meio da Capes $1 / \mathrm{UAB}$, há dificuldades de orçamento para manter esses cursos, que, por não serem criados e oferecidos pelo Ministério da Educação

A partir de 2007, com a Lei n⿳ 11.502, que modificava a Lei $n^{\circ} 8.405$, de 1992, a Capes passou a subsidiar e dar suporte ao desenvolvimento de atividades de apoio à formação de profissional de magistério para a Educação Básica, objeto prioritário da UAB (BRASIL, 2007). 
(MEC), não passam pelo aval do Ministério do Planejamento e não fazem parte do orçamento da União para a contratação de professores e demais servidores. O MEC disponibiliza algumas vagas para professores trabalharem prioritariamente com cursos a distância, mas estes não são vinculados aos cursos da mesma forma como seriam em cursos presenciais. Eles podem ser professores coringa (que atuam em diversos cursos) ou especialistas em Informática e Multimídias. Esse problema foi percebido em pesquisa realizada por Pimenta e Lopes (2014) com docentes do curso de Pedagogia a distância da Universidade de Brasília (UNB), em que os entrevistados viam dificuldades nessa não institucionalização dos cursos do sistema $\mathrm{UAB}$, de forma que esses cursos representavam algo secundário na universidade. Um dos entrevistados chegou a sugerir que, "se houvesse reconhecimento do trabalho que faz na UAB como um trabalho próprio da UNB", ele abriria mão da bolsa que recebe por esse trabalho (PIMENTA; LOPES, 2014, p. 282). Outra dificuldade para o professor que não é vinculado aos cursos de EAD é que ele não se especializa nessa modalidade de ensino (por exemplo, no uso de tecnologias), o que, segundo pesquisa de Nunes e Sales (2013, p. 765) realizada com professores do curso de Pedagogia da Universidade Estadual do Ceará - UECE/UAB, "tende a implicar um ensino de menor qualidade".

Nas IPES parceiras do MEC, no acordo de oferta de cursos superiores a distância, há dificuldade na constituição e no desenvolvimento de cursos de graduação que não são financiados pelo MEC. Desta forma, a abertura de turmas e de cursos restringe-se a editais de chamadas propostos pela Capes/UAB. Como os cursos não são institucionalizados organicamente, tornam-se atividades secundárias para a própria Instituição de Ensino Superior (IES). Nas IPES, como os alunos dos cursos de EAD "não são computados na matriz orçamentária das instituições públicas de Ensino Superior, os programas terminam por não serem instituídos de fato nelas" (ALONSO, 2010, p. 1328).

Os polos de apoio presencial (Municípios, Estados e o Distrito Federal), os outros parceiros nessa oferta, são responsáveis pela infraestrutura para o funcionamento de cursos de Ensino Superior, principalmente a construção e manutenção de laboratórios específicos, de bibliotecas com acervo especializado e internet compatível com o ensino a distância, que demandam recursos financeiros de alto custo para os municípios. "Evidente que a maior parte dos municípios brasileiros tem pouca chance de implementar, com qualidade, tais polos" (ALONSO, 2010, p. 1331). Alonso cita relatório do Tribunal de Contas da União a que teve acesso em 2009, em que são apresentados dados de implementação dos polos presenciais da UAB, sobretudo "sobre a fragilidade da parceria IES e municípios" (ALONSO, 2010, p. 1331). Na parte final do relatório, constatou-se "risco de sustentabilidade do sistema" em decorrência de os polos e as instituições não estarem "suficientemente 
instrumentalizados para organizar e ministrar os programas de formação". Também se relata que a infraestrutura física é deficiente nos polos de apoio presencial, além de apresentar problemas no sistema de tutoria, justamente na articulação do tutor com o professor, que é visto pelo Tribunal como um supervisor do trabalho do tutor (ALONSO, 2010, p. 1332).

Como os cursos de graduação criados e desenvolvidos por esse acordo tripartite de colaboração não são regulares, eles funcionam de acordo com a demanda observada pela Capes/UAB, com algumas regras para a oferta, que são ditadas por meio de editais.

As principais dificuldades de os cursos não serem regulares e a oferta ser feita por meio de editais estão relacionadas ao número mínimo de vagas exigidas pela UAB para que os cursos sejam aprovados para serem ofertados pelas IPES. Além disso, a abertura de turmas fica subordinada às demandas da Capes/UAB. No Edital de Chamada UAB 03/2013 2014/01 2014.2 (Capes, 2013), Articulação de cursos no sistema UAB, que esclarece e regulariza a oferta de cursos a distância para o primeiro semestre de 2014 e o segundo semestre de 2014, o subitem 1.4 condiciona a aprovação a algumas exigências.

Como se pode ver no Quadro, para que um curso de "graduação com necessidade de ambiente acadêmico específico" seja aprovado pela UAB e receba as verbas

Quadro. Articulação de cursos Capes/UAB.

\begin{tabular}{|c|c|c|}
\hline $\begin{array}{l}\text { Mínimo de } \\
\text { vagas por curso }\end{array}$ & Nível/tipo de curso & Área \\
\hline 100 & $\begin{array}{l}\text { Graduação com necessidade de } \\
\text { ambiente acadêmico específico }\end{array}$ & $\begin{array}{c}\text { Ciências, Biologia, Química, } \\
\text { Física, Artes Visuais ou Plásticas } \\
\text { e Educação Física }\end{array}$ \\
\hline \multirow{2}{*}{125} & $\begin{array}{l}\text { Graduação sem necessidade de } \\
\text { ambiente acadêmico específico }\end{array}$ & $\begin{array}{c}\text { Todas, exceto as que } \\
\text { necessitam de ambiente } \\
\text { específico }\end{array}$ \\
\hline & $\begin{array}{c}\text { Formação ou complementação } \\
\text { pedagógica }\end{array}$ & Todas \\
\hline \multirow{3}{*}{150} & Especialização & \multirow{3}{*}{ Todas } \\
\hline & Aperfeiçoamento & \\
\hline & Extensão & \\
\hline
\end{tabular}

Fonte: Capes (2013). 
para funcionamento da Capes (bolsas para professores, bolsas para tutores, verbas para produção de material didático), o mínimo de vagas que devem ser ofertadas é 100; para um curso de "graduação sem necessidade de ambiente acadêmico específico", o mínimo é 125 . O número de alunos de no mínimo 100 para cursos como Biologia ou 125 para cursos de Pedagogia é excessivo para possibilitar a interação direta entre professor e aluno.

Não basta ter professores e alunos no exercício da mediação. Se a tentativa desse exercício se der numa relação de 100 alunos para 1 professor, por exemplo, por mais eficientes que as TIC dispostas no sistema possam ser - e não o são -, será impossível sustentar processos de formação responsáveis, considerando somente as demandas dos alunos. Mesmo com a miríade de oferta dos denominados ambientes virtuais de aprendizagem, que facilitariam a organização das informações dispostas aos alunos, absolutamente estaria descartado trabalho especializado e de recursos humanos formados especialmente para esse tipo de atendimento (ALONSO, 2010, p. 1327).

Segundo Abreu-e-Lima e Alves (2011, p. 190), em pesquisa realizada tendo como objeto de estudo cursos a distância promovidos pela Universidade Federal de São Carlos, integrante do sistema UAB, o "grande número de estudantes" nesses cursos não permite o trabalho de qualidade de professores. Aparece para cumprir com essa função a figura de um novo profissional da educação, o tutor:

O professor sozinho não consegue administrar com qualidade um número cada vez maior de estudantes em salas de aulas virtuais, e, dessa forma, surge nesse contexto um novo profissional no trabalho docente: professor-tutor (ABREU-E-LIMA; ALVES, 2011, p. 190).

O acompanhamento do aluno por um processo de tutoria estava presente no âmago de criação da UAB, quando a instituição promoveu o seu primeiro curso-piloto, Administração, no ano de 2005, que contava com um grande número de estudantes:

O estudante será acompanhado por um processo de tutoria que permitirá, de acordo com dizeres de tal projeto, "o monitoramento direto do desempenho e do fluxo de atividades, facilitando 
a interatividade e identificação de possíveis dificuldades de aprendizagem (ZUIN, 2006, p. 943).

Nesse momento, aparentemente, a tutoria teria a função de monitorar o desempenho e o fluxo de atividades dos estudantes, bem como o de facilitar a interatividade e a identificação de possíveis dificuldades de aprendizagem. Isso é um projeto do ano de 2005, anterior, alguns meses, ao Decreto $\mathrm{n}^{\circ} 5.800$ (BRASIL, 2006), que institucionaliza a UAB, que é de 2006; do mesmo ano é o Decreto $\mathrm{n}^{\circ} 5.622$ (BRASIL, 2005), que regulamentou a EAD e incluiu a relação entre professor e aluno na caracterização da educação a distância, em substituição ao Decreto ${ }^{\circ}$ 2.494 (BRASIL, 1998), que considerava o aluno um autoaprendiz. Em suma, esse novo ator social no processo de ensino e aprendizagem na educação a distância surgiu no momento em que as inovações tecnológicas permitiram a interação entre professor e aluno na rede de computadores.

\section{0 professor e o professor-tutor na interação entre educador e educando}

No sistema de ensino organizado pela UAB, há duas categorias de tutor: o tutor presencial e o tutor a distância. Eles ocupam lugares diferentes no processo de ensino e aprendizagem: o tutor a distância fica na Instituição que promove o curso, distante do estudante e próximo do professor. É ele quem atua na sala de aula virtual. O tutor presencial fica no polo de apoio presencial, no município polo, mais próximo do estudante, longe do professor, e atua com um contato mais efetivo com o aluno, nem tanto no ambiente virtual, mas no polo (PRETI; OLIVEIRA, 2003). Os tutores não têm vínculo trabalhista com as instituições, recebem bolsa, são selecionados por meio de editais e contratados após avaliação. $\mathrm{Na}$ lista de suas atribuições determinadas pela Capes/UAB para fazerem jus à bolsa, notamos a importância dos tutores.

As atribuições do tutor são:

Mediar a comunicação de conteúdos entre o professor e os cursistas; acompanhar as atividades discentes (grifo nosso), conforme o cronograma do curso; apoiar o professor da disciplina no desenvolvimento das atividades docentes; estabelecer contato permanente com os alunos e mediar as atividades discentes (grifo nosso); colaborar com a coordenação do curso na avaliação dos estudantes; participar das atividades de capacitação e atualização promovidas pela Instituição de Ensino; elaborar relatórios mensais de 
acompanhamento dos alunos e encaminhar à coordenação de tutoria; participar do processo de avaliação da disciplina sob a orientação do professor responsável (BRASIL, 2010).

O tutor a distância, professor-tutor, teria papel de facilitador do processo de ensino e aprendizagem, mediando a comunicação entre professor e aluno. No entanto, com a quantidade excessiva de estudantes por turma para o professor, de 100 a 125 para 1 , o tutor que tem sob seu acompanhamento 25 alunos torna-se responsável por manter contato direto com o aluno, "acompanhando mais sistematicamente o desempenho de cada um desses alunos sob sua responsabilidade" (ABREU-E-LIMA; ALVES, 2011, p. 191). Desse modo, se o tutor é quem acompanha o aluno, trabalha cotidianamente com ele, participa do processo de avaliação das aprendizagens do curso etc. (ALONSO, 2010, p. 1330), não há diferença entre a sua atuação e a do docente, a não ser pelo fato de que não foi ele quem preparou a disciplina, produziu o material didático, elaborou as atividades para serem desenvolvidas pelos alunos ou formulou as avaliações, que são obrigações do professor. Isso constitui um problema para o desenvolvimento dos cursos ofertados pelo sistema $\mathrm{UAB}$, pois o agente que tem a principal função de interação direta com os alunos, acompanhando seu desenvolvimento, não preparou o curso, não tendo, ainda, "profissionalmente reconhecimento social/econômico/empregatício compatível com essas atribuições" (ALONSO, 2010, p. 1330).

Os professores elaboram o material didático da disciplina. $\mathrm{A} U \mathrm{UB}$ não relaciona no rol de atribuições do professor pesquisador conteudista que ele poste as atividades no ambiente virtual, "o professor deve elaborar e 'entregar' (grifo nosso) os conteúdos dos módulos desenvolvidos ao longo do curso no prazo determinado" para o coordenador do curso (BRASIL, 2010). Os professores, segundo o que determina o Fundo para Desenvolvimento da Educação - FNDE (BRASIL, 2010), devem preparar como material didático, comumente, textos teóricos da disciplina, disponíveis em artigos eletrônicos, livros ou e-books ou digitalizados; elaborar videoaulas explicativas dos assuntos, ou de revisão; criar atividades; disponibilizar links com filmes e documentários; realizar webaulas; estabelecer contato com os estudantes, ainda que de forma indireta, entre outros recursos midiáticos. As atividades propostas pelo professor têm alguma variedade, podem ser objetivas e subjetivas e contam com a participação dos tutores, que têm sob sua orientação 25 alunos por turma, o que possibilita contato e acompanhamento direto dos alunos, responsabilidade que, como foi visto, lhe é atribuída pela Capes/UAB (CAPES, 2009). Para facilitar o trabalho dos tutores a distância, os professores devem orientá-los, segundo o que exige o FNDE (BRASIL, 2010). Os tutores, com as orientações do professor, informam os alunos sobre seu desempenho nas atividades, por meio de feedback: "Procedimento de comunicação realizada para 
informar o aprendiz sobre a acuidade de sua resposta, geralmente relacionada a uma pergunta instrucional" (ABREU-E-LIMA; ALVES, 2011, p. 191).

No feedback dos tutores aos alunos aparecem alguns problemas para a EAD. Alguns são de ordem geral da própria linguagem escrita no computador, que limita um tanto o debate, mesmo para os professores virtuais, pois os feedbacks escritos não têm o mesmo calor, a mesma emoção, os gestos, a postura, as expressões faciais do professor, os movimentos corporais da linguagem oral, da aula presencial, ainda que se tenha os

emoticon (emoção + ícones), uma sequência de caracteres tipográficos ou uma imagem pequena que traduz ou procura transmitir o estado psicológico, emotivo, de quem o emprega, simulando uma expressão facial (ABREU-E-LIMA; ALVES, 2011, p. 193).

A dificuldade maior, porém, ocorre porque o professor-tutor não é o professor responsável pela disciplina e a interação dele com o aluno - realizada por meio de feedback tendo como suporte algumas orientações do professor (um gabarito, talvez) - limita consideravelmente o desenvolvimento dos alunos em todas as atividades, sobretudo em conhecimentos reflexivos, que exigem interpretação, diálogo, dialética. O feedback é muito mais um diálogo motivador do tutor com o aluno do que uma forma de interação efetiva, que deveria ser realizada, em tempos de educação on-line, do aluno com o professor. Em pesquisa com alunos evadidos do curso a distância (piloto) de Administração da UFAL, Bittencourt e Mercado (2014, p. 487) atestaram como aspectos negativos do curso que os alunos "foram unânimes em fazer críticas aos tutores". No entendimento dos autores, quanto menor for o desempenho do tutor, maior é o índice de alunos evadidos. No tocante ao desempenho negativo dos tutores, os alunos alegaram, em resposta ao questionário formulado pelos pesquisadores, que eles não tinham domínio do conteúdo e não tinham formação na área da disciplina específica (BITTENCOURT; MERCADO, 2014). Críticas negativas à atuação dos tutores estão relacionadas à atribuição de responsabilidades incompatíveis para a função do tutor, que deveria promover a mediação entre o professor, responsável pelo domínio dos conteúdos e especialista na disciplina ofertada, e o aluno. Os alunos evadidos disseram também que a motivação e o feedback dos tutores não foram satisfatórios. Os pesquisadores consideram que o papel da tutoria no início do curso piloto de Administração deixou a desejar nos quesitos domínio, motivação e feedback (BITTENCOURT; MERCADO, 2014), uma vez que os tutores não eram da área nem tinham experiência com EAD. Esse problema com os tutores foi revertido, segundo os autores da pesquisa, no segundo ano do curso, quando 
foram contratados tutores "com experiência em EAD e com formação específica nas disciplinas do curso" (BITTENCOURT; MERCADO, 2014, p. 495). No entanto, em pesquisa recente realizada com docentes do curso de Pedagogia a distância da UNB, Pimenta e Lopes (2014, p. 282) concluíram que "o professor supervisor age dependendo muito da comunicação com os tutores e do comportamento destes" e, para agravar esse quadro, o contrato com os tutores, o sistema de bolsas de tutoria, de valor muito baixo e de curto período de duração, provoca grande rotatividade de profissionais, o que gera uma situação de precarização do trabalho do professor-tutor. É um trabalho que parece ser sempre temporário, mas que acaba por se perenizar (PIMENTA; LOPES, 2014).

Outra função delegada aos tutores a distância é a apreciação das atividades e avaliações (PRETI, 2008). Faz parte das atribuições do tutor "participar do processo de avaliação da disciplina sob orientação do professor responsável" (BRASIL, 2009). A avaliação do desempenho dos estudantes deve ser delegada aos tutores, seja nas atividades, nos fóruns, nos exercícios ou na avaliação presencial, porque é ele que acompanha mais de perto o desenvolvimento do aluno ao longo da disciplina (PRETI, 2008).

A avaliação presencial deve ser feita obrigatoriamente pelo aluno no polo de apoio presencial; deve ser, segundo o que determina o artigo $4^{\circ}$ do Decreto $\mathrm{n}^{\circ} 5.622$ (BRASIL, 2005), a maior nota entre todas as atividades realizadas a distância:

II - Realização de exames presenciais.

$\S 1^{\circ}$ Os exames citados no inciso II serão elaborados pela própria instituição de ensino credenciada, segundo procedimentos e critérios definidos no projeto pedagógico do curso ou programa.

$\S 2^{\circ}$ Os resultados dos exames citados no inciso II deverão prevalecer sobre os demais resultados obtidos em quaisquer outras formas de avaliação a distância.

Essa exigência traz alguns problemas para os alunos, sobretudo aqueles que escolheram fazer um curso a distância justamente pela flexibilização de tempo e espaço. Pelo menos uma vez por disciplina, o estudante deve se dirigir ao polo de apoio presencial para realizar uma atividade que será a nota que deverá prevalecer sobre as outras obtidas durante o curso, ou seja, segundo a lei, os cursos a distância ofertados no Brasil e, obviamente, pelo sistema UAB são, na verdade, semipresenciais. A avaliação presencial, que tem de ser formulada pelo professor 
da disciplina, que elaborou o conteúdo e o material didático, traz dificuldades para os tutores a distância, pois estes acompanharam o desenvolvimento dos estudantes durante todo o processo de ensino e podem ser responsabilizados pelo professor e pelos próprios alunos em caso de reprovação na disciplina. Também, nesse caso, é atribuição do professor fazer "orientações para os tutores" sobre a avaliação (BRASIL, 2010).

O tutor presencial exerce função diferente do tutor a distância: ele é responsável pelo acompanhamento dos estudantes nos polos; ele precisa ter conhecimentos de informática e de internet, pois seu papel principal é ajudar os alunos presencialmente a usar esses recursos; deve ser graduado no curso em que faz a tutoria, para poder ajudar os alunos, que podem recebê-los presencialmente e auxiliá-los em assuntos relacionados com as disciplinas (PRETI, 2008). Os tutores presenciais têm a tarefa, também, de aplicar as atividades presenciais, algumas vezes junto com os tutores a distância, que se deslocam para os polos. Os tutores presenciais ajudam nas aulas práticas de laboratórios, nos cursos que demandam essas práticas. Esse é o caso do curso de Biologia. Os laboratórios específicos são outro complicador da EAD, pois aulas práticas de laboratório tornam o curso semipresencial, mas não contam com a presença do professor. Outra atividade do tutor presencial é de animador dos estudantes, promovendo encontros presenciais para estudo em grupo, ficando em contato com alunos que estão se evadindo (PRETI, 2008). No polo de apoio presencial, a educação a distância se assemelha à presencial, com espaço físico e encontro face a face entre os envolvidos no processo de ensino e aprendizagem. Arieira et al. (2009, p. 334) atestaram, em pesquisa realizada com acadêmicos de um curso de Administração presencial em que foram oferecidas disciplinas a distância, que é "grande a valorização do espaço físico da sala de aula e da presença do professor no Ensino Superior". No caso dos cursos superiores a distância of ertados pelo sistema UAB, o polo transforma-se simbolicamente no espaço físico da sala de aula e o tutor presencial, por vezes, toma o lugar do professor.

\section{Considerações finais}

As novas tecnologias de informação e comunicação, sobretudo a internet, trouxeram possibilidades reais para o sistema UAB promover educação a distância interativa, on-line. Há possibilidade de interação do professor com seus alunos, dos alunos entre si, de tutores com alunos e professores. Essa interação é mediada pelas tecnologias de informação e comunicação em webconferências, fóruns, entre outros recursos, que tornam a relação entre os envolvidos no processo educativo mais intersubjetiva do que aquela em que o professor era um produtor de aula para consumo e o estudante um autoaprendiz. O estudante 
dos cursos superiores oferecidos pelo sistema UAB não está mais solitário em sua aprendizagem e pode encontrar-se com seus colegas de turma, de polo e até de outros polos, assim como encontrar seus tutores a distância, no ambiente virtual, para um aprender colaborativo, que o professor pode acompanhar e do qual pode, efetivamente, participar. Essa relação interativa e colaborativa é essencial para o processo de ensino e aprendizagem, principal argumento em defesa da educação a distância.

Há algumas críticas a essa interação mediada pela máquina, pelo computador, pois que ela limitaria o diálogo, a dialética. A resposta às questões formuladas pelos estudantes é respondida pelo professor utilizando o código binário, a escrita no computador. Essa forma de linguagem modifica em muito as relações intersubjetivas, pois entre estudante e professor há, segundo Zuin (2006), um meio de comunicação secundário e não primário como as aulas presenciais. Existe, também, a preocupação de que o uso de tecnologias na educação demanda daqueles que a estão empregando conhecimentos aprimorados que, segundo Nunes e Sales (2013), muitos usuários do processo educativo não têm ou, segundo Belloni (2003), para os quais não foram preparados.

No entanto, os avanços de cursos de Ensino Superior na modalidade a distância on-line oferecidos pelo sistema UAB são inegáveis quando comparados à educação a distância de pronta entrega (broadcast). É possível, por meio de recursos on-line e webconferência, por exemplo, que o professor responda questões formuladas pelos estudantes diretamente e, portanto, de forma primária. Mesmo que na relação entre professor e estudante se interponha uma tecnologia de informação e comunicação, na relação de ensino e aprendizagem este é o meio de comunicação primaz de nossos tempos, sendo "indiscutível o papel cada vez mais significativo que as tecnologias assumem na socialização dos indivíduos nas sociedades modernas" (NUNES; SALES, 2013, p. 757). Além disso, "negar a produção técnica como fruto do trabalho humano seria o mesmo que admitir a impossibilidade de se utilizar o potencial emancipatório da própria técnica para conversão histórica do reino da necessidade no reino da liberdade" (ZUIN, 2006, p. 950). O problema é saber, então, se a tecnologia é utilizada de modo adequado para promover a emancipação de todos os envolvidos no processo educativo ou se "depende exclusivamente do livre arbítrio de quem a 'controla"” (ZUIN, 2006, p. 951).

No caso dos cursos ofertados pelo sistema $\mathrm{UAB}$, analisando estudos de caso em Pimenta e Lopes (2014), Bittencourt e Mercado (2014), Abreu-e-Lima e Alves (2013), constatou-se que, na realidade, os cursos superiores oferecidos 
pelo sistema apresentam diversos problemas quando se reflete sobre os avanços possibilitados pelas novas tecnologias de informação e comunicação on-line, no que diz respeito, sobretudo, à interação entre professor e estudante. A não institucionalização dos cursos superiores à distância nas Instituições Públicas de Ensino Superior, sendo os cursos oferecidos por um convênio de cooperação tripartite, talvez seja o fator complicador a não permitir uma revolução educacional nos cursos superiores a distância. Os cursos, não sendo institucionalizados nas IPES, tornam-se secundários. Os professores não são contratados especificamente para esses cursos e não se sentem pertencentes aos cursos a distância ofertados por suas IPES, tendo essa tarefa como atividade extra. No estudo de Pimenta e Lopes (2014) notou-se, claramente, que os docentes se sentem secundários na relação de ensino e aprendizagem. Outro problema é que a quantidade de estudantes por turma e de polos é determinada por meio de editais lançados pela $\mathrm{UAB}$, não estando vinculados aos projetos pedagógicos dos cursos ofertados. Nos editais, a UAB exige um número excessivo de vagas e de polos para que o curso seja aberto, como foi atestado no edital 2014/1 e 2014/2. No estudo de Abreu-e-Lima e Alves (2013), verificou-se que os professores não têm condições de interagir com os alunos, pelo grande número de alunos e polos. O tutor a distância, então, que deveria ser um mediador entre professor e estudante, assume o papel do professor na interação com os alunos, trabalhando com estratégias e metodologias de ensino, material didático e processos avaliativos elaborados pelos professores. Esse tutor se torna professor-tutor (ABREU-E-LIMA E ALVES, 2013) que não tem vínculo trabalhista com a instituição, recebe uma bolsa e acompanha o desenvolvimento do aluno, inclusive na avaliação (PRETI, 2008).

No formato da EAD de cursos de graduação oferecidos pelo sistema UAB, o documento de criação do sistema mostra que os objetivos desse órgão são expandir e interiorizar, reduzir a desigualdade na oferta de cursos superiores no Brasil, além de resolver os problemas de falta de professores licenciados em algumas disciplinas do Ensino Básico. Esses objetivos foram estabelecidos mais pelas necessidades em aumentar a oferta de vagas para o Ensino Superior público e para resolver a falta de professores para a Educação Básica do que para explorar os avanços que as novas tecnologias de informação e comunicação podem oferecer para a educação a distância. O fato é que ampliar os espaços e tempos educacionais com o auxílio da lógica provida pelos cursos on-line não promove, só por isso, uma revolução educacional (OLIVEIRA, 2010, p. 108). É fundamental que professores elaborem suas disciplinas, com estratégias pedagógicas, metodologias de ensino, material didático, utilizando os avanços das novas tecnologias, de modo que possibilite a interação com seus alunos e um trabalho colaborativo (OLIVEIRA, 2010). 
Podemos, então, afirmar que, em relação à oferta de cursos pelo sistema UAB, pode ser apresentada a mesma crítica que Corbucci (2004, p. 683) faz à expansão de cursos de graduação centrada na iniciativa privada, dos anos de 1997 a 2002: "Não constitui condição suficiente para assegurar a democratização do acesso à formação em nível superior". Não será a modalidade de educação a distância, no formato quantitativo e não institucionalizado nas IPES, como é ofertado pelo sistema UAB, condição suficiente para a democratização, expansão e interiorização de cursos superiores no Brasil, muito menos para a redução da desigualdade na oferta de vagas no Ensino Superior público.

Os cursos superiores na modalidade a distância, quando criados, deveriam seguir os mesmos trâmites e condições dos cursos superiores presenciais, sendo diferentes apenas nos meios de comunicação e tecnologias que utilizam. Deste modo, o Ensino Superior público a distância estaria na mesma medida do Ensino Superior público presencial e poderia entrar na Reforma da Educação Superior do MEC, iniciada no ano de 2004, cuja proposta reconhece, justamente, que a "democratização desse nível de ensino não se reduz à mera expansão de oferta de vagas" (CORBUCCI, 2004, p. 696). 


\title{
The Open University of Brazil and the democratization of public higher education
}

\begin{abstract}
This study surveyed the progress and limits of distance education in higher education courses offered by the Open University system in Brazil. It seeks to analyze decrees-law and official documents regulating the distance education in Brazil as well as the creation of the Open University of Brazil (UAB) as a public policy of expansion, democratization, and internalization of public higher education. We also studied through Capes/UAB and also FNDE (Fund for Development of Education) documents the role of the new social actor who appears in the teaching and learning of the top courses in the distance education: the tutor. It was found that the higher education distance courses promoted by the UAB system bring important advances to the distance education when compared to the traditional distance education that employed static media such as television, radio, books, as a communication language, particularly the possibilities of interpersonal relations.
\end{abstract}

Keywords: Distance education. Distance higher education. Educational technology. Education online.

\section{La Universidad Abierta de Brasil y la democratización de la educación superior pública}

\section{Resumen}

Resumen: Este estudio examinó los avances y los límites de la educación a distancia en cursos de educación superior que ofrece el sistema de la Universidad Abierta de Brasil. Busca analizar los decretos-ley y documentos oficiales que regulan la educación a distancia en Brasil, así como la creación de la Universidad Abierta de Brasil (UAB) como una política pública de la expansión, la democratización, y la internalización de la educación superior pública. También se estudia, en documentos de la Capes/UAB y del FNDE, el Fondo para el Desarrollo de la Educación, el papel del nuevo actor social que aparece en la enseñanza y el aprendizaje a distancia: el tutor. Se encontró que los cursos superiores a distancia promovidos por el sistema de la UAB traen importantes avances a la educación a distancia en comparación con la educación a distancia tradicional, que empleaba como lengua de comunicación medios estáticos, como la televisión, radio, libros, especialmente en las posibilidades de relaciones interpersonales. Sin embargo, estos también presentan algunas limitaciones.

Palabras clave: Educación a distancia. Educación Superior a distancia. La tecnología educativa. La educación en línea. 


\section{Referências}

ABREU-E-LIMA, D. M.; ALVES, M. N. O feedback e sua importância no processo de tutoria a distância. Pró-Posições, v. 22, n. 2 (65), p. 189-205, maio/ago. 2011. http://doi.org/10.1590/S0103-7307201100020001

ADORNO, T. W.; HORKHEIMER, M. Dialética do esclarecimento: fragmentos filosóficos. Rio de Janeiro: Jorge Zahar, 1985.

ALMEIDA, M. E. B. Educação a distância na internet: abordagens e contribuições dos ambientes digitais de aprendizagem. Educação e Pesquisa, v. 29 , n. 2, p. 327-40, jul./dez. 2003.

ALONSO, K. M. A expansão do ensino superior no Brasil e a EAD. Dinâmicas e Lugares. Educação e Sociedade, v. 31, n. 113, p. 1319-35, out./dez. 2010.

ARAÚJO, M. M. S. O pensamento complexo: desafios emergentes para a educação on-line. Revista Brasileira de Educação. v.12, n. 36, set./dez. 2007.

ARIEIRA, J. O. et al. Avaliação do aprendizado via educação a distância: a visão dos discentes, Ensaio: Avaliação, Politicas Públicas em Educação, v. 17, n. 63, p. 313-40, abr/jun, 2009.

BEHRENS, M. A. Projetos de aprendizagem colaborativa num paradigma emergente. In: MORAN, J. M.; MASETTO, M. T.; BEHRENS, M. A. Novas tecnologias e mediações pedagógicas. Campinas: Papirus, 2000.

BELLONI, M. L. Educação a distância. 3. ed. Campinas: Autores Associados, 2003. (Coleção Educação contemporânea).

BENJAMIN, W. Magia e técnica, arte e política: ensaios sobre literatura e história da cultura. 7. ed. São Paulo: Brasiliense, 1994. (Obras escolhidas, 1).

BITTENCOURT, I. M.; MERCADO, L. P. L. Evasão nos cursos na modalidade de educação a distância: estudo de caso do Curso Piloto de Administração da UFAL/UAB. Ensaio: Avaliação, Política Pública em Educação, v. 22, n. 83, p. 465-504, abr.jun. 2014.

BRANDÃO, C. R. O que é educação. 17. ed. São Paulo: Brasiliense, 1981.

BRASIL. Decreto No 2.494, de 10 de fevereiro de 1998. Regulamenta o artigo 80 da Lei ${ }^{\circ}$ 9.394, de 20 de dezembro de 1996, e dá outras providências.

Diário Oficial da União, 11 fev; 1998. 
BRASIL. Decreto $\mathrm{n}^{\circ}$ 5.622, de 19 de dezembro de 2005. Regulamenta o art. 80 da Lei no 9.394, de 20 de dezembro de 1996, que estabelece as diretrizes e bases da educação nacional. Diário Oficial da União, 20 dez. 2005.

. Decreto $\mathrm{n}^{\mathrm{0}} 5.800$, de 8 de junho de 2006. Dispõe sobre o Sistema Universidade Aberta do Brasil - UAB. Diário Oficial da União, 9 jun. 2006.

. Decreto $\mathrm{n}^{\mathrm{o}} 11.502$, de 11 de julho de 2007. Modifica as competências e a estrutura organizacional da fundação Coordenação de Aperfeiçoamento de Pessoal de Nível Superior - CAPES, de que trata a Lei no 8.405, de 9 de janeiro de 1992; e altera as Leis nos 8.405, de 9 de janeiro de 1992, e 11.273, de 6 de fevereiro de 2006, que autoriza a concessão de bolsas de estudo e de pesquisa a participantes de programas de formação inicial e continuada de professores para a educação básica. Diário Oficial da União, 12 jul. 2007.

. Lei $\mathrm{N}^{\circ}$ 9.394, de 20 de dezembro de 1996. Estabelece as diretrizes e bases da educação nacional. Diário Oficial da União, 23 dez. 1996.

. Lei $\mathrm{N}^{\circ} 10.172$, de 9 de janeiro de 2001. Aprova o Plano Nacional de Educação e dá outras providências. Diário Oficial da União, 10 jan. 2001.

. Ministério da Educação. Fundo Nacional de Desenvolvimento da Educação - FNDE. Resolução $N^{o} 08$, de 30 de abril de 2010. Altera os incisos I a V do art. $9^{\circ}, \mathrm{o} \S 1^{\circ}$ do art. 10 e o item 2.4 do Anexo I da Resolução $\mathrm{CD} / \mathrm{FNDE} \mathrm{n}^{\circ} 26 / 2009$, que estabelece orientações e diretrizes para o pagamento de bolsas de estudo e de pesquisa a participantes da preparação e execução dos cursos dos programas de formação superior, inicial e continuada no âmbito do Sistema Universidade Aberta do Brasil (UAB). Diário Oficial da União, 3 maio 2010.

. Ministério da Educação. Fundo Nacional de Desenvolvimento da Educação - FNDE. Resolução $N^{\circ} 26$, de 5 de junho de 2009. Estabelece orientações e diretrizes para o pagamento de bolsas de estudo e de pesquisa a participantes da preparação e execução dos cursos dos programas de formação superior, inicial e continuada no âmbito do Sistema Universidade Aberta do Brasil (UAB), vinculado à Coordenação de Aperfeiçoamento de Pessoal de Nível Superior (Capes), a serem pagas pelo FNDE a partir do exercício de 2009. Diário Oficial da União, 8 jun. 2009.

CAPES. Chamada UAB 2013. Articulação de cursos no sistema UAB (2013/2 2014/1). Brasília, DF, 2013. Disponível em: <http://www.ufrgs.br/sead/editais/ documentos/chamada-uab-03-2013>. Acesso em: mar. 2014. 
CAPES. Formulário de cadastramento de bolsistas da universidade aberta do Brasil. Brasília, DF, 2009.

CORBUCCI, P. R. Financiamento e democratização do acesso à educação superior no Brasil: da deserção do Estado ao projeto de reforma. Educação \& Sociedade, v. 25, n. 88, p. 677-701, out. 2004. http://doi.org/10.1590/S0101-73302004000300003

FREIRE, P. Pedagogia do oprimido. 18. ed. Rio de Janeiro: Paz e Terra, 1988. LÉVY, P. Cibercultura. São Paulo: Editora 34, 1999.

MORAN. J. M. A educação que desejamos: novos desafios e como chegar lá. Campinas: Papirus, 2007.

NUNES, J. B. C.; SALES, V. M. B. Formação de professores de licenciatura a distância: o caso do curso de pedagogia da UAB/UECE. Educação e Pesquisa, São Paulo, v. 39, n. 3, p. 757-773, jul./set. 2013. http://doi.org/10.1590/S1517-97022013000300013

OLIVEIRA, G. P. Estratégias multidimensionais para a avaliação da aprendizagem em cursos on line. Ensaio: Avaliação e Políticas Públicas em Educação, v. 18, n. 66, p. 105-38, jan./mar. 2010. http://doi.org/10.1590/S0104-40362010000100007

PATTO, M. H. S. O ensino a distância e a falência da educação. Educação e Pesquisa, v. 39, n. 2, p. 303-18, abr.jun. 2013. http://doi.org/10.1590/S1517-97022013000200002

PIMENTA, A. M.; LOPES, C. Habitus professoral na sala de aula virtual. Educação em Revista, v. 30, n. 3, p. 267-89, jul./set. 2014. http://doi.org/10.1590/S1517-97022013000200002

PLATÃO. Fedro em diálogos. Belém: Universidade Federal do Pará, 1975.

PRETI, O. Avaliação da aprendizagem em cursos a distância: "Delegando responsabilidade aos tutores"? In: CONGRESSO DE ENSINO SUPERIOR A DISTANCIA, 5.; SEMINÁRIO NACIONAL DE EAD, 6., 2008, Gramado. Disponível em: < http://uab.ufmt.br/uploads/pcientifica/avaliacao_ aprendizagem.pdf $>$. Acesso em: ago. 2015.

PRETI. O.; OLIVEIRA, G. M. S. O sistema de orientação acadêmica no curso de pedagogia a distância da Universidade Federal de Mato Grosso, como parte do projeto "Les susthémes d'appui à l'étudiant dans Le domainede la Formation à Distance: le tutorat”. Quebec: Téléuniversité du Québec, 2003. 
SEGENREICH, S. C. D. ProUni e UAB como estratégias de EAD na expansão do ensino superior. Pro-Posições, v. 20, n. 2, p. 205-22, maio/ago. 2009. http://doi.org/10.1590/S0103-73072009000200013

ZUIN, A. A. S. Educação a distância ou educação distante? O Programa Universidade Aberta do Brasil, o tutor e o professor virtual. Educação \& Sociedade, v. 27, n. 96, p. 935-54, out. 2006. http://doi.org/10.1590/S0101-73302006000300014

\section{Informações do autor}

Paulo Romualdo Hernandes: Doutor em Educação. Professor do Programa de Pós-Graduação em Educação da Universidade Federal de Alfenas. Contato: paulorh_ mancini@hotmail.com 